\title{
A Rede EPT na perspectiva inclusiva: uma revisão sistemática da literatura sobre formação continuada docente
}

\author{
Daniele Pinheiro Volante ${ }^{1}$ \\ Luana Ugalde da Costa ${ }^{2}$ \\ Suammy Priscila Rodrigues Leite Cordeiro ${ }^{3}$
}

\begin{abstract}
Resumo:
Trata-se de revisão sistemática de pesquisas que objetivou analisar trabalhos que relacionem formação continuada docente $(F C D)$ e inclusão de estudantes com deficiência $(E c D)$ no ensino técnico integrado ao ensino médio dos Institutos Federais (IFs). A pesquisa justifica-se pela composição dos corpos docentes nos IFs, pelo descompasso entre o acesso dos EcD e a formação docente, e pela escassez de pesquisas sobre o tema. Foram utilizados o Portal de Periódicos da Capes, a Biblioteca Digital Brasileira de Teses e Dissertações e a plataforma Google Acadêmico na busca, resultando em dez publicações que evidenciaram: a escassez de pesquisas, distribuídas em sete dos 38 IFs, a concentração de resultados em 2017 e no IFRN; e a percepção de descompasso entre o discurso sobre educação inclusiva nos documentos institucionais e a prática possível nas instituições como motivação comum aos achados. Por fim, os resultados e as conclusões evidenciaram a necessidade de fortalecimento e oferta contínua da FCD nos IFs, para a consolidação de uma educação inclusiva efetiva a todos os estudantes, e de aumento das pesquisas de mesmo tema para enriquecimento e divulgação de conhecimento na área da educação especial em uma perspectiva inclusiva.
\end{abstract}

\section{Palavras-chave:}

Educação inclusiva. Formação continuada do professor. Instituto Federal.

\footnotetext{
1 Especialização em Educação Profissional e Tecnológica inclusiva pelo Instituto Federal do Triângulo Mineiro (IFTM). Técnica em Assuntos Educacionais no Instituto Federal do Paraná (IFPR). E-mail: danielepvolante@gmail.com. ORCID iD: http://orcid.org/0000-0002-4589-6512.

2 Mestre em Ensino Tecnológico pelo Programa de Mestrado Profissional em Ensino Tecnológico do Instituto Federal do Amazonas (IFAM). Docente de Psicologia e Coordenadora de Ações inclusivas no Instituto Federal do Acre (IFAC). E-mail: luana.costa@ifac.edu.br. ORCID iD: http://orcid.org/00000001-5332-8956.

3 Doutoranda em Educação. Formação de Professores pela Universidade de Lisboa (UL). Docente de Libras no Instituto Federal do Mato Grosso (IFMT). E-mail: suammy.cordeiro@ifmt.edu.br. ORCID iD: http://orcid.org/0000-0002-3019-5799.
} 


\section{PTE Network on the inclusive perspective: a systematic review about teacher continuing education}

\section{Abstract:}

This is a systematic review of research projects aiming to analyze publications about Teacher Continuing Education (TCE) and inclusion of students with disabilities in technical high school courses from the Federal Institute of Science, Education and Technology (FIs). This study is justified by the composition of the faculty in Fls, by the mismatch between access of disabled students and teacher education, and by the small amount of research about this theme. Were used Capes Journal Portal, Brazilian Theses and Dissertations Digital Library and Google Scholar platform in research, what resulted in ten publications that evidenced: the scarcity of results, distributed in seven out of 38 Federal Institutes; the concentration of results in 2017 and at Federal Institute of Rio Grande do Norte; and the perception of mismatch between the inclusive education portrayed in institutional documents and what is possible to achieve as a common motivation for the findings. Finally, the results and conclusions evidenced the need of TCE as a consolidated and permanent policy, to achieve an inclusive education for all students, and other research on the same subject to enrich and disseminate knowledge in Special Education in an inclusive perspective.

\section{Keywords:}

Inclusive education. Teacher continuing education. Federal Institute.

\section{La Red EPT en la perspectiva inclusiva: una revisión sistemática de la literatura acerca de la formación continua del profesorado}

\section{Resumen:}

Se trata de una revisión sistemática de la producción científica que tuvo como objetivo analizar trabajos que relacionan la formación continua del profesorado (FCP) y la inclusión de estudiantes con discapacidad (EcD) en la educación técnica integrada al nivel secundario de los Institutos Federales (IF). El estudio se justifica por la composición del profesorado en las IF, por el desajuste entre el acceso de los EcD y la formación docente, y por la escasez de investigación sobre el tema. En la búsqueda se utilizó el Portal de Revistas Capes, la Biblioteca Digital Brasileña de Tesis y Disertaciones y la plataforma Google Académico, dando como resultado diez publicaciones que mostraron: la escasez de estudios, distribuidos en siete de las 38 IF, la concentración de resultados en 2017 y en el Instituto Federal de Rio Grande do Norte; y la percepción de desajuste entre el discurso de la Educación Integrada en los documentos institucionales y la posible práctica en las instituciones como una motivación común para los hallazgos. Finalmente, los resultados y conclusiones destacaron la necesidad de fortalecer y ofrecer continuamente la FCP en las IF, con el fin de consolidar una educación inclusiva efectiva para todos los estudiantes, y aumentar la investigación sobre la misma temática para enriquecer y difundir conocimientos en la Educación especial en la perspectiva inclusiva.

Palabras clave:

Educación inclusiva. Formación continua del profesorado. Instituto Federal.

\section{Introdução}

Nos últimos anos, como resultado da luta pelos direitos das pessoas com deficiência (PcDs), a legislação brasileira tem sido bastante assertiva, com a publicação de diversos dispositivos legais 
e normativos que garantem a inclusão de estudantes público-alvo da educação especial (PAEE) ${ }^{4}$ nos mais diversos espaços da vida em sociedade.

Os exemplos mais recentes dessas conquistas no que diz respeito ao acesso à educação, são: a Lei ${ }^{\circ}$ 13.146, de seis de julho de 2015, que reforça a responsabilidade das instituições de ensino na implementação do "atendimento educacional especializado" e na "[...] adoção de medidas individualizadas e coletivas [...] que maximizem o desenvolvimento acadêmico e social dos estudantes com deficiência, favorecendo o acesso, a permanência, a participação e a aprendizagem" (BRASIL, 2015b, Art. 28, Alínea V); a reserva de vagas para PcDs nos cursos de nível médio e superior das instituições federais de ensino pela Lei no 13.409, de 28 de dezembro de 2016 (BRASIL, 2016); e, ainda, obtida por meio da Ação Direta de Inconstitucionalidade nº 6590, a suspensão da eficácia do Decreto $\mathrm{n}^{\circ} 10.502$, de trinta de setembro de 2020 , que permitia a retomada do modelo segregatório de educação especial, adotado até meados da década de 1970 (BRASIL, 2020c; 2020f).

Faz-se necessário esclarecer que a "educação especial", neste trabalho, é entendida conforme definida por Mazzotta (2011), como modalidade de ensino caracterizada pelos recursos e serviços educacionais especializados organizados com a finalidade de apoiar, suplementar e, em casos específicos, substituir os serviços educacionais comuns e com o objetivo de garantir o processo educativo de estudantes com necessidades educacionais específicas e diversas daquelas apresentadas pela maioria das pessoas. E, a partir de tal entendimento, compreende-se a "inclusão" como processo fundamentado no combate à "prática de homogeneização dos seres humanos a partir da compreensão da diversidade humana" (MOURA, 2013, p. 41) e na organização das instituições de ensino de maneira a propiciar condições de aprendizagem a todos seus estudantes, atendendo, assim, às necessidades educacionais destes em sua diversidade (JANNUZZI, 2012).

\section{A formação de professores para atuação na perspectiva inclusiva}

Como resultado dos avanços legais quanto à garantia de acesso de $\mathrm{EcD}$, nota-se o crescimento das matrículas de estudantes PAEE na rede comum e, em específico, na Rede EPT, que conta com 4.420 das 5.994 matrículas totais para cursos de ensino técnico integrado ao ensino médio nas redes federal, estadual e particular no ano de 2019 (BRASIL, 2020d; BRASIL, 2020e).

Entretanto, a readequação do processo formativo docente parece não acompanhar essa realidade. Encontram-se, ainda, diversos cursos de licenciatura com uma organização curricular que atende apenas ao mínimo previsto na legislação para a formação docente em uma perspectiva de educação inclusiva (MÔNICO; MORGADO; ORLANDO, 2018; BASSO; CAMPOS, 2019; KÖNIG, 2019), o que resulta em professores inseguros quanto a lecionar em turmas com EcD (MENEZES et al., 2016) e possível prejuízo na aprendizagem desse alunado.

É relevante observar que a indicação da presença de conhecimentos relativos à educação especial nos cursos de formação docente ocorre a partir das Diretrizes Curriculares Nacionais para a Formação de Professores da Educação Básica (DCNs) de 2002, a Resolução CNE/CP n 1, de dezoito de fevereiro de 2002 (BRASIL, 2002), mas que a "obrigatoriedade da formalização" desses conhecimentos na organização curricular desses cursos ocorre somente treze anos depois, com a publicação da Resolução CNE/CP n 2, de primeiro de julho de 2015 (BRASIL, 2015a). As DCNs de 2015, porém, ainda não definem a carga horária mínima desses componentes, o que ocorre apenas na Resolução n 2, de vinte de dezembro de 2019 (BRASIL, 2020a).

Sobre o atendimento educacional adequado de estudantes PAEE, Borba (2020, p. 7) ressalta que o docente precisa estar "[...] disposto diariamente a mudar as práticas pedagógicas, as ferra-

4 De acordo com a Política Nacional de Educação Especial na perspectiva da educação inclusiva, o PAEE são estudantes com deficiência, transtornos globais do desenvolvimento e altas habilidades/superdotação (BRASIL, 2008). 
mentas de intervenção e até mesmo utilizar-se de estratégias diferenciadas para elaborar recursos que facilitem a aprendizagem". Mas, para que o professor identifique as diferentes necessidades educacionais dos estudantes PAEE e o modo como serão realizadas as adaptações metodológicas e curriculares, é imprescindível uma formação que lhe permita "[...] refletir sobre seu novo papel e as novas demandas introduzidas pela educação inclusiva, e [...] efetivar mudanças que colaborem para a inclusão de alunos com deficiência em sala de aula" (COSTA, 2018, p. 48).

Diante do descompasso entre o acesso de estudantes PAEE e a adequação da formação docente para o atendimento das necessidades educacionais desse alunado, pode-se esperar que a efetivação da educação especial na perspectiva da educação inclusiva apresente-se como um grande desafio para as escolas, principalmente para as da rede de educação profissional e tecnológica (Rede EPT), composta majoritariamente pelos Institutos Federais de Educação, Ciência e Tecnologia (IFs), devido à diversidade na composição de seus corpos docentes e pelo número expressivo de matrículas de estudantes PAEE.

\section{Os IFs e a educação especial na Rede EPT: realidades e desafios}

Criados pela Lei no 11.892 , de 29 de dezembro de 2008, os IFs oferecem educação profissional e tecnológica baseada na articulação da prática pedagógica e dos conhecimentos científicos e tecnológicos com objetivo, entre outros, de emancipação cidadã dos indivíduos (BRASIL, 2008). Atuam em diversos níveis e modalidades de ensino, mas, conforme os objetivos estabelecidos por sua lei de criação, devem priorizar cursos de ensino técnico integrado ao ensino médio, foco desta pesquisa.

Devido à natureza dos cursos técnicos integrados ao ensino médio, os colegiados de curso são formados por docentes oriundos de cursos de licenciatura, que lecionam nas diversas áreas do conhecimento que compõem as disciplinas do ensino médio, e, também, por servidores com formação em áreas distintas, em cursos de bacharelado ou tecnólogo (OLIVEIRA, 2016). Uma vez que, segundo o Art. 10, $\S 1^{\circ}$ da Lei $n^{\circ} 12.772$, de 28 de dezembro de 2012, o requisito mínimo para investidura no cargo de Professor Docente de Educação Básica, Técnica e Tecnológica é a graduação na área em que lecionará (BRASIL, 2012), muitos professores não tiveram contato com conhecimentos científicos que tratam dos processos pedagógicos, de desenvolvimento humano e de ensino-aprendizagem, obrigatórios em cursos de Licenciatura e Pedagogia, e tampouco tiveram contato com aqueles relacionados à educação especial em uma perspectiva inclusiva (OLIVEIRA, 2016).

Outra particularidade da Rede EPT, os Núcleos de Atendimento às Pessoas com Necessidades Específicas (Napnes) são fruto do Programa TEC NEP - Educação, Tecnologia e Profissionalização para Pessoas com Necessidades Especiais. Eles foram criados como "principal lócus de atuação do processo de inclusão" (BRASIL, 2009, p. 17) e para tornarem-se centros de referência no atendimento e acompanhamento de $\mathrm{EcD}$, visando à inclusão, permanência e êxito de $\mathrm{PcDs}$ nos cursos da educação profissional e tecnológica (COSTA, 2018). Anjos (2006) explica que esses núcleos são responsáveis pela articulação de ações com a finalidade de garantir a acessibilidade e desenvolver uma cultura de respeito à diversidade e eliminação de barreiras arquitetônicas, atitudinais e educacionais.

Apesar dos objetivos originais serem pouco abrangentes, as demandas trazidas pelos estudantes e a mudança na realidade dos campi ao longo da trajetória dos IFs ampliou o escopo de atuação dos Napnes, conforme destaca Costa (2018). A autora traz como atividades passíveis ao Napne a identificação dos EcD e de suas necessidades educacionais específicas, a orientação do corpo docente sobre as adaptações metodológicas necessárias, a criação e adequação de materiais didáticos acessíveis, o planejamento e a execução de ações de ensino, pesquisa e extensão que visem à divulgação de informações sobre a educação especial, a promoção de uma cultura de respeito à diversidade e, por fim, o planejamento e a formação de servidores da instituição para atuarem em uma perspectiva inclusiva. 


\section{Outras pesquisas relacionadas}

A fim de identificar as contribuições da produção acadêmica e possíveis lacunas de pesquisa, realizou-se uma exploração inicial nas bases de dados de acesso público Portal de Periódicos da Capes, Biblioteca Digital Brasileira de Teses e Dissertações e Portal de Periódicos da Scielo. A procura foi realizada a partir de dois grupos de descritores: "Instituto Federal, formação continuada e estudantes com deficiência" e "Instituto Federal, formação continuada e Napne". O espaço temporal utilizado foi entre os anos de 2009 - ano posterior à criação dos IFs - e 2019 - ano anterior ao início da presente pesquisa.

Como resultado, foram obtidas apenas quatro publicações, disponíveis na Biblioteca Digital Brasileira de Teses e Dissertações. A publicação mais antiga, de 2014, discorre sobre práticas educativas inclusivas observadas nas turmas de educação de jovens e adultos do Instituto Federal do Espírito Santo - campus Vitória - e sobre o papel do Napne para a inclusão dos estudantes PAEE (SILVA, 2014). As duas publicações de 2017, consistem no comparativo entre as condições de acessibilidade nas instituições de ensino superior no estado do Acre (FREITAS, 2017) e em uma proposta de formação continuada sobre a educação especial em uma perspectiva inclusiva voltada para docentes do ensino médio comum e integrado ao ensino técnico (NORONHA, 2017). A publicação mais recente, de 2018, é o relato de uma iniciativa de formação continuada para coordenadores dos Napnes do Instituto Federal do Acre (COSTA, 2018).

Diante do descompasso entre as políticas públicas para o acesso dos estudantes PAEE e para a formação docente, da realidade distinta dos IFs e, ainda, da lacuna de pesquisa evidenciada, torna-se relevante a realização de pesquisas que abordem as iniciativas de formação continuada de professores para a educação especial em uma perspectiva inclusiva dentro da Rede Federal de ensino. E o fortalecimento, a partir da construção de conhecimento, de uma temática que se mostrou pouco explorada, justifica a realização de pesquisas relacionadas a esse assunto, como é o caso deste trabalho.

O presente artigo parte do seguinte problema de pesquisa: de que forma os IFs promovem a formação continuada docente (FCD) voltada à inclusão de estudantes PAEE, matriculados em seus cursos técnicos integrados ao ensino médio?

Foi estabelecido, como objetivo principal, apresentar e analisar trabalhos que relacionem FCD e a inclusão de EcD do ensino técnico integrado ao ensino médio dos IFs, e, a partir desses pressupostos, iniciou-se esse trabalho conforme os procedimentos metodológicos descritos a seguir.

\section{Método}

Este estudo buscou apresentar e analisar as produções acadêmicas publicadas no período entre janeiro de 2017 e fevereiro de 2020, que abordem a FCD voltada ao atendimento dos estudantes $\mathrm{EcD}$, matriculados no ensino técnico integrado ao ensino médio dos IFs. A pesquisa foi desenvolvida com base em uma revisão sistemática da literatura, de abordagem mista, e se propôs a responder os seguintes questionamentos: 1) Essa é uma temática recorrente? 2) Existem áreas de concentração para essas pesquisas? 3) Existem fatores em comum aos trabalhos que possam ter motivado as pesquisas dessa temática?

Tashakkori e Creswell (2007) definem pesquisas de métodos mistos como trabalhos nos quais pesquisadores usam abordagens quantitativas e qualitativas para coletarem e analisarem dados, integrando resultados para delimitar conclusões. Rosa, Oliveira e Orey (2015) complementam que, aplicando estratégias presentes em métodos qualitativos e quantitativos para responder às questões que direcionaram a pesquisa, pode-se utilizar contextos observados nos documentos analisados para justificar, explicar ou corroborar os dados quantitativos obtidos. 
Quanto ao método de revisão sistemática da literatura, este objetiva responder questões por meio de um levantamento de trabalhos publicados que sejam relacionados a um tema específico, tornando a busca mais eficiente e resultando em uma análise reflexiva, crítica e compreensiva do material levantado (COSTA; ZOLTOWSKI, 2014). Para levantamento dos dados, foram seguidas as oito etapas indicadas pelos autores: definição da(s) questão(ões) central(is) da pesquisa; escolha $\mathrm{da}(\mathrm{s})$ fonte(s) de dados; escolha dos descritores a serem utilizados na busca; busca e armazenamento dos resultados iniciais; seleção dos resultados a partir de critérios de inclusão e exclusão pré-definidos; obtenção de dados; avaliação do material levantado resultante; e síntese e interpretação dos dados, conforme detalhados a seguir.

Considerando as questões centrais indicadas anteriormente, foi realizada a busca inicial utilizando o Portal de Periódicos da Capes, a Biblioteca Digital Brasileira de Teses e Dissertações e o Portal de Periódicos da Scielo, utilizadas anteriormente na exploração inicial da temática. No intuito de ampliação de busca, também foi usada a plataforma Google Acadêmico.

Quanto aos descritores, sua escolha foi realizada com a intenção de torná-los “[...] sensíveis o suficiente para acessar adequadamente o fenômeno, indicando um número representativo de trabalhos [...]", mas não "[...] sensíveis demais, retornando muitos resultados, inviabilizando o projeto de revisão" (COSTA; ZOLTOWSKI, 2014, p. 61). Portanto, no intuito de refinar a busca e aproximar o quanto fosse possível os resultados da questão proposta, foram estipulados seis termos que referenciam o problema do presente estudo, distribuídos em quatro grupos distintos, descritos no Quadro 1.

Com o mesmo objetivo de refinamento de busca, foi incluído como critério adicional o período de publicação entre os anos de 2017 e 2020. Foi escolhido analisar somente trabalhos publicados entre 2017 e fevereiro de 2020, por ser o período compreendido entre a determinação de reserva de vagas a estudantes PAEE pela Lei no 13.409 (BRASIL, 2016), e seus efeitos, possivelmente, estimularem as produções acadêmicas na área da educação especial em uma perspectiva inclusiva, e o mês anterior à suspensão das atividades pedagógicas presenciais nas instituições de ensino brasileiras como meio de prevenção ao contágio por Covid-19 e a consequente adoção do ensino remoto emergencial (BRASIL, 2020b). Dessa forma, foi garantido que os achados analisados não fossem o resultado das necessidades recentes de FCD evidenciadas pela reestruturação dos cursos, frente à pandemia e, em consequência, oriundas de contexto distinto daquele inerente à realidade do ensino presencial.

Por meio da busca inicial, chegou-se a 275 achados (273 na plataforma Google Acadêmico, um resultado no Portal de Periódicos da Capes, um resultado na Biblioteca Digital Brasileira de Teses e Dissertações e nenhum resultado encontrado no Portal de Periódicos da Scielo), distribuídos pelos grupos de descritores utilizados, conforme Quadro 1.

Quadro 1: Número de produções encontradas para cada grupo de descritores utilizado

\begin{tabular}{|l|c|c|}
\hline Grupo & Descritores utilizados & Resultados \\
\hline Grupo 1 & $\begin{array}{c}\text { Inclusão, Instituto Federal, Ensino Médio Integrado e } \\
\text { Formação Continuada de Professores }\end{array}$ & 229 produções \\
\hline Grupo 2 & $\begin{array}{r}\text { Inclusão, Instituto Federal, Ensino Médio Integrado, } \\
\text { Formação Continuada Docente }\end{array}$ & 27 produções \\
\hline Grupo 3 & $\begin{array}{c}\text { Inclusão, Instituto Federal, Ensino Técnico Integrado ao } \\
\text { Ensino Médio, Formação Continuada de Professores }\end{array}$ & 2 produções \\
\hline Grupo 4 & $\begin{array}{c}\text { Inclusão, Instituto Federal, Ensino Técnico Integrado ao } \\
\text { Ensino Médio, Formação Continuada Docente }\end{array}$ \\
\hline
\end{tabular}

Fonte: Elaborado pelas autoras com base em dados da pesquisa. 
Como etapa seguinte para obtenção de resultados válidos à questão pesquisada, os achados iniciais foram armazenados em editor de planilhas para aplicação dos critérios de exclusão e inclusão, definidos previamente, e títulos condizentes aos critérios de exclusão foram eliminados do grupo de trabalhos que seriam analisados.

Quanto aos critérios de inclusão, era necessário a pesquisa ter sido escrita em língua portuguesa, publicada entre os anos de 2017 e fevereiro de 2020, e ser condizente com a temática do presente trabalho; foram considerados critérios de exclusão, além do não atendimento às premissas anteriores, a duplicidade de resultados, indisponibilidade da publicação e a não correspondência a todos os descritores utilizados na busca.

Por fim, os trabalhos resultantes dessa triagem foram avaliados por meio de leitura, sintetizados e interpretados. Partindo das questões norteadoras, optou-se por analisar as produções, inicialmente, sob os aspectos de temporalidade, distribuição e motivação, com seis categorias relacionando-se a eles: ano de publicação, natureza da produção (temporalidade), local de aplicação do estudo (distribuição), recorte temático da produção, abrangência do tema dentro da educação inclusiva e contexto gerador da pesquisa (motivação).

\section{Resultados}

Após a triagem dos resultados iniciais, por meio da leitura dos resumos dessas produções e da aplicação dos critérios de inclusão e exclusão, houve redução expressiva na quantidade de trabalhos a serem analisados. É necessário esclarecer que, mesmo utilizando descritores para refinamento de busca, diversos resultados iniciais eram relacionados a apenas parte dos descritores do grupo.

Assim, além dos resultados repetidos ou indisponíveis, foram excluídas as produções que tratavam somente de adaptações curriculares, as que abordavam a formação continuada para docência em nível ou modalidade de ensino diferentes do ensino técnico integrado ao ensino médio (ensino fundamental, ensino médio, ensino técnico subsequente e ensino superior) e as que possuíam, como lócus de pesquisa, escolas técnicas das redes municipal ou estadual. Como exemplos de aplicação dos critérios de exclusão mencionados, foram descartados trabalhos que tratavam sobre a FCD em cursos de ensino técnico integrado ao ensino médio, mas na rede estadual ou municipal e, também, pesquisas sobre a FCD nos cursos de ensino superior dos IFs.

Ao final, foi levantado um total de nove resultados que abordaram a FCD para atendimento das necessidades educacionais de estudantes PAEE matriculados em cursos técnicos integrados ao ensino médio ofertados pelos IFs. Esses nove resultados englobam dez produções acadêmicas distintas, uma vez que um dos resultados corresponde a uma coletânea de resumos e artigos, com dois resumos que atendem aos critérios de inclusão, conforme se observa na Tabela 1.

Tabela 1: Distribuição dos resultados analisados sob o aspecto de temporalidade e categorizados de acordo com o ano de publicação e natureza da publicação

\begin{tabular}{|l|c|c|c|c|c|}
\hline \multirow{2}{*}{ Ano } & \multicolumn{5}{|c|}{ Produções que atendem os critérios de inclusão } \\
\cline { 2 - 6 } & \multirow{2}{*}{ Total } & \multicolumn{4}{|c|}{ Natureza das produções } \\
\cline { 2 - 6 } & & Resumo & Artigo & Dissertação & Tese \\
\hline 2017 & 7 & 2 & 0 & 3 & 2 \\
\hline 2018 & 2 & 0 & 1 & 1 & 0 \\
\hline 2019 & 1 & 0 & 1 & 0 & 0 \\
\hline 2020 & 0 & 0 & 0 & 0 & 0 \\
\hline
\end{tabular}

Fonte: Elaborado pelas autoras com base em dados da pesquisa. 
Das produções acadêmicas encontradas, são maioria as publicações que ocorreram no ano de 2017 (sete publicações), não havendo resultados para o ano de 2020. É possível observar, portanto, que a reserva de vagas para o PAEE na Rede EPT, ao final de 2016, não interferiu nas pesquisas e nos registros de oferta de FCD para atendimento desse alunado, uma vez que ocorreu redução na quantidade de trabalhos publicados ao longo do período. Ainda, apenas três dos trabalhos analisados mencionam a existência de reserva de vagas a estudantes PAEE nas instituições onde ocorreram a pesquisa (NORONHA, 2017; LIRA, 2018; SANTOS, 2018), mas somente uma autora relata tal reserva como resultado direto da Lei no 13.409, de 28 de dezembro de 2016 (LIRA, 2018). Em relação à natureza das pesquisas, as dissertações de mestrado aparecem em maior número (quatro trabalhos), porém não muito distante da quantidade de achados para resumos, artigos e teses (dois trabalhos). Tais informações apontam que a temática não é recorrente ou mais atrativa aos pesquisadores de uma etapa específica de formação.

Além do ano e formato das produções acadêmicas apresentadas sobre o tema, também foram identificados os locais de realização das pesquisas. Observou-se uma prevalência maior de produções nos Institutos Federais do Rio Grande do Norte (IFRN) e Goiano (IFGoiano), com três e dois trabalhos, respectivamente, como é indicado no Quadro 2. Com exceção das duas instituições citadas, foi encontrado apenas um resultado para cada um dos outros IFs que serviram de lócus de pesquisa: Instituto Federal do Amazonas (IFAM), Instituto Federal da Bahia (IFBA), Instituto Federal Baiano (IFBaiano), Instituto Federal de Goiás (IFG) e Instituto Federal do Triângulo Mineiro (IFTM).

Quadro 2: Resultados analisados sob os aspectos de distribuição e temporalidade, categorizados de acordo com a instituição onde ocorreu a pesquisa, autores, ano de publicação e natureza da produção

\begin{tabular}{|c|c|c|}
\hline Instituto Federal & Produções & Natureza da publicação \\
\hline IFRN & $\begin{array}{c}\text { ALENCAR, } 2017 \\
\text { FORTES, } 2017 \\
\text { LIRA, } 2018\end{array}$ & $\begin{array}{l}\text { Dissertação } \\
\text { Tese } \\
\text { Artigo }\end{array}$ \\
\hline IFGoiano & $\begin{array}{c}\text { MACEDO; SILVA, } 2017 \\
\text { SOUZA; ALMEIDA XIMENES, } 2017\end{array}$ & $\begin{array}{l}\text { Resumo } \\
\text { Resumo }\end{array}$ \\
\hline IFAM & NORONHA, 2017 & Dissertação \\
\hline IFBA & SANTOS, 2018 & Dissertação \\
\hline IFBaiano & FERREIRA, 2017 & Tese \\
\hline IFG & LIMA et al., 2019 & Artigo \\
\hline IFTM & BELCHIOR, 2017 & Dissertação \\
\hline
\end{tabular}

Fonte: Elaborado pelas autoras com base em dados da pesquisa.

Para as duas instituições com mais de uma contribuição, é preciso observar alguns aspectos importantes. Os resultados encontrados para o IFGoiano (MACEDO; SILVA, 2017; SOUZA; ALMEIDA; XIMENES, 2017), apresentam complexidade muito menor em relação aos demais achados (resumos) e fazem parte de uma mesma revista que funciona, nas palavras de seu texto de apresentação, como registro escrito de um evento institucional que objetiva ser espaço para relato de "[...] experiências exitosas com distintas abordagens desenvolvidas nas unidades do IFGoiano na tentativa de promover a reflexão da prática cotidiana [...] com vistas à melhoria da qualidade de ensino" (MONTEIRO et al., 2017, p. 7). Esses registros são, portanto, fruto de uma política institucional que tenta oportunizar a seu quadro de servidores espaço para divulgação de iniciativas e práticas em educação e, também, troca de experiências entre servidores da instituição, tornando-se, em si mesmo, ambiente formativo. 
Ressalta-se a ineficácia dessa política no que diz respeito à temática deste artigo, assim como à educação especial e à FCD de formas isoladas, visto a pequena quantidade de registros apesar do espaço oportunizado pela instituição. Dentre os 39 trabalhos publicados por ela - 23 resumos simples e dezesseis resumos expandidos - somente dois resumos simples abordam a FCD para atendimento do PAEE (achados que foram analisados), dois são relatos de iniciativas inclusivas na instituição e nenhum dos demais trabalhos versa sobre FCD no IFGoiano.

Já as publicações do IFRN são iniciativas individuais de pesquisadores da instituição, publicadas nos anos 2017 e 2018, e referentes a diversas etapas formativas: um artigo escrito como trabalho de conclusão de curso para graduação, uma dissertação de mestrado e uma tese de doutorado (ALENCAR, 2017; FORTES, 2017; LIRA, 2018). A concentração de trabalhos no IFRN pode estar relacionada ao histórico da instituição, enquanto Gestor Regional do Programa TEC NEP para a Região Nordeste. De acordo com Anjos (2006), os gestores regionais tinham o papel de, em sua região, coordenar o processo de implantação do Programa TEC NEP e expansão das oportunidades de formação de PcDs por meio da Rede EPT, assim como de capacitar recursos humanos para o atendimento adequado desse público. Considerando que os três achados analisados referenciam pesquisas anteriores, sobre educação especial em uma perspectiva inclusiva, ambientadas no IFRN, é possível que o Programa TEC NEP tenha contribuído para que a instituição continuasse a desenvolver pesquisas sobre inclusão mesmo após o encerramento do programa.

Quanto ao recorte temático adotado nos achados, dos dez trabalhos analisados, sete são diretamente relacionados à FCD, consistindo em quatro relatos de ofertas (FERREIRA, 2017; FORTES, 2017; MACEDO; SILVA, 2017; SOUZA et al., 2017) e três levantamentos de demanda por FCD (NORONHA, 2017; LIRA, 2018; SANTOS, 2018). Os demais resultados correspondem a levantamentos das políticas institucionais para a educação inclusiva que indicam, entre elas, a FCD (ALENCAR, 2017; BELCHIOR, 2017; LIMA et al., 2019).

Dentre os quatro relatos de oferta mencionados, Ferreira (2017) e Fortes (2017) abordaram especificamente a deficiência visual (DV) a fim de atender, em seus ambientes de pesquisa, a necessidades imediatas evidenciadas pelo ingresso recente de estudantes com DV; os outros pesquisadores (MACEDO; SILVA, 2017; SOUZA et al., 2017) propuseram uma formação voltada à educação especial em uma perspectiva inclusiva com o objetivo de contribuir com o corpo docente no atendimento educacional de estudantes PAEE já matriculados e de ingresso futuro.

Esses trabalhos indicaram a pertinência do assunto, por serem conhecimentos teóricos e práticos pouco conhecidos pela maioria dos participantes e relataram resultados positivos após a oferta, envolvendo mudanças no planejamento docente, como a adequação no tempo disponibilizado para realização das atividades avaliativas e a adoção dos materiais adaptados propostos, assim como algumas mudanças atitudinais (FORTES, 2017; MACEDO; SILVA, 2017). Macedo e Silva (2017) observaram a melhora no desempenho dos estudantes acompanhados pelo Napne e Souza et al. (2017) ressaltaram a necessidade de aprofundamento em assuntos específicos dentro da temática em momento futuro, em complemento à ação registrada. Os resultados corroboram o trabalho de Jesus e Effgen (2012), que menciona a necessidade de um espaço formativo, preferencialmente na própria instituição de ensino, para que os docentes possam garantir ensino de qualidade a todos os seus estudantes.

Nos três trabalhos de levantamento de demanda para FCD, os entrevistados reconhecem a necessidade e o interesse em FCD para o atendimento de estudantes PAEE. Porém, destaca-se a pesquisa de Santos (2018), que chama a atenção para o caráter inclusivo do IFBA/campus Jacobina no que diz respeito às questões étnicas, raciais, de gênero e sexualidade, mas alerta que o mesmo não acontece em relação à inclusão de PcDs. A autora sugere a ausência de um número expressivo de PAEE como razão para esse contexto e reforça a necessidade de FCD para docência em turmas com estudantes EcD, matriculados à época da pesquisa e futuros ingressantes. 
O planejamento motivado pela necessidade parece ser bastante comum, conforme evidenciado nos trabalhos de levantamento de ações institucionais (ALENCAR, 2017; BELCHIOR, 2017; LIMA et al., 2019). Apresenta-se, na fala de alguns dos entrevistados, o entendimento de que a discussão de estratégias para efetivação de uma educação inclusiva a todos os sujeitos deve acontecer somente após estabelecimento de demanda específica. Tal percepção equivocada pode inviabilizar o planejamento de estratégias para a acolhida desses estudantes desde o momento de seu ingresso e pode contribuir com a sensação de despreparo relatada pelos docentes entrevistados nos achados e já mencionado por Menezes et al. (2016) quando ocorrer o ingresso de um estudante PAEE.

Quanto à existência de fatores comuns que possam ser considerados como estímulo à pesquisa nessa temática, dois fatores destacaram-se na maioria dos trabalhos. Conforme mencionado, o reconhecimento da instituição como Gestor Regional do Programa TEC NEP para a Região Nordeste e Centro de Referência no Atendimento de Pessoas com Necessidades Específicas no estado, e a preocupação em aperfeiçoar o atendimento ofertado, por meio da realização de pesquisas sobre inclusão e educação especial em uma perspectiva inclusiva ao longo da trajetória da instituição, são fatos que permeiam os três achados do IFRN (ALENCAR, 2017; FORTES, 2017; LIRA, 2018). É fato que foram encontrados apenas essas três publicações que abordem a FCD para atendimento de estudantes, mesmo durante o levantamento de lacunas de pesquisa, mas a instituição tem contribuído para o fortalecimento de outros aspectos na área da educação especial em uma perspectiva inclusiva, que não a FCD, segundo referenciado pelas autoras.

O segundo e mais importante fator observado é a percepção, pelas autoras, de distanciamento entre o discurso institucional acerca da educação inclusiva e prática observada por elas na instituição, evidenciada na escrita de Alencar (2017), Belchior (2017), Fortes (2017), Noronha (2017) e Santos (2017). Na contextualização de suas pesquisas, as autoras partem do reconhecimento da responsabilidade institucional na oferta de FCD para a efetivação de uma educação inclusiva a todos os estudantes, presente nos documentos institucionais, e da dúvida acerca da possibilidade de materialização dessa responsabilidade para a proposição e execução de suas pesquisas.

\section{Conclusões}

Com o objetivo de realizar um levantamento das produções que relacionem a FCD e EcD, matriculados em cursos de ensino técnico integrado ao ensino médio da Rede EPT, buscou-se identificar trabalhos publicados entre os anos de 2017 e fevereiro de 2020, e categorizá-los sob os aspectos de temporalidade, distribuição e motivação.

Em relação à primeira categoria, foi encontrado um baixo número de produções acadêmicas, presentes de forma irregular ao longo do período analisado, com pouca diferença de quantidade entre os tipos das publicações encontradas. Devido à quantidade dos trabalhos, a distribuição irregular das pesquisas ao longo do período analisado e da natureza variada das produções, não é possível, portanto, apontar a temática como recorrente ou como mais atrativa a pesquisadores em uma etapa específica de sua trajetória acadêmica. Diante da queda do número de trabalhos encontrados no decorrer do período analisado, também é possível afirmar que a reserva de vagas para estudantes PAEE na Rede EPT não contribuiu para o aumento da oferta e do registro de FCD para atendimento desse alunado.

Sobre a distribuição dos trabalhos pelos IFs, a maioria das instituições apresentou apenas uma contribuição para o assunto e somente duas instituições (IFGoiano e IFRN) apresentaram dois e três trabalhos, respectivamente. Devido à complexidade reduzida dos registros ambientados no IFGoiano e pela quantidade de pouca relevância frente aos trabalhos de outras temáticas 
oriundos do mesmo evento institucional, que, portanto, receberam os mesmos incentivos para sua divulgação, não se pode considerar a existência de uma concentração de pesquisas em educação especial em uma perspectiva inclusiva no IFGoiano.

Em contrapartida, as pesquisas ambientadas no IFRN são iniciativas individuais, publicadas em dois dos três anos completos que compõem o recorte temporal, resultado de diferentes etapas formativas e, para as pesquisas ligadas a programas de pós-graduação, oriundas de programas distintos. Desse modo, é possível concluir que existe uma concentração de pesquisas sobre a FCD para atendimento de estudantes PAEE no IFRN, mesmo que em pequeno número.

E, considerando a quantidade de pesquisas anteriores sobre inclusão e atendimento de $\mathrm{EcD}$ ambientadas no IFRN que embasaram os achados analisados, também é possível concluir que a consolidação de uma área de pesquisa em determinada instituição é bastante importante como estímulo para a realização de outras pesquisas na mesma área e pode se configurar como um dos fatores motivadores para esses trabalhos, última categoria de análise.

Ainda em relação à motivação dos trabalhos, os resultados evidenciaram a percepção de distanciamento entre o discurso sobre educação inclusiva presente em documentos institucionais e a realidade na instituição como principal fator motivador dos achados, mencionado pela maioria dos autores. Conclui-se que os efeitos do descompasso observado entre a garantia de acesso à educação para estudantes PAEE e o preparo do corpo docente para o atendimento adequado de suas necessidades educacionais é uma preocupação relevante aos pesquisadores da educação especial em uma perspectiva inclusiva, por interferir diretamente na permanência e no êxito dos EcD.

Portanto, apesar da ausência de estudantes PAEE no ambiente de pesquisa ser usada como justificativa para a inexistência ou inconsistência de FCD para a educação especial na perspectiva da educação inclusiva em alguns achados, a justificativa deixa de ser plausível ao observarmos: 1) o principal fator motivador das pesquisas; 2) o quantitativo de matrículas da educação especial na Rede EPT, que constata a presença massiva desse alunado nos IFs; 3 ) a possibilidade de ingressos de futuros de estudantes PAEE; 4) a manutenção de uma cultura de respeito à diversidade e a emancipação cidadã dos indivíduos como objetivos do Napne dos IFs.

É possível, ainda, que a percepção da discrepância entre intenção e realidade, constatada como principal fator motivador dos achados desta pesquisa, inquiete outros pesquisadores, mas estes sejam confrontados com aspectos que dificultem a execução de pesquisas sobre essa temática ou o registro das iniciativas de FCD. Sugere-se, dessa forma, a realização de pesquisas que abordem os fatores que dificultem ou impeçam a implantação da FCD para a educação especial na perspectiva da educação inclusiva de forma consistente nos IFs, assim como fatores de interferências na atuação dos Napnes. É necessário ressaltar que as limitações deste trabalho em relação à quantidade de achados poderiam ser minimizadas por outros autores que ampliassem o recorte temporal, o nível e a modalidade de ensino abordadas, dadas as características de alguns dos trabalhos descartados pelos critérios de exclusão aqui adotados.

Por fim, como possível contribuição deste trabalho à comunidade acadêmica e científica, confia-se que os dados apresentados possam evidenciar demandas (por pesquisas da temática abordada neste trabalho e por mais iniciativas de fluxo contínuo para FCD em educação especial em uma perspectiva inclusiva), incoerências (nas políticas institucionais de formação continuada de servidores), e que subsidiem o aprofundamento de estudos sobre o contexto, a proposição e a divulgação de iniciativas exitosas de FCD voltadas ao atendimento educacional adequado de EcD do ensino técnico integrado ao ensino médio dos IFs. 


\section{Referências}

ALENCAR, Ligyanne Karla de. Politicas públicas de inclusão de pessoas com deficiência na educação profissional: ações e possibilidades no Instituto Federal de Educação, Ciência e Tecnologia do Rio Grande do Norte. 2017. Dissertação (Mestrado em Educação) - Instituto Federal do Rio Grande do Norte, Natal, 2017. Disponível em: https://memoria.ifrn. edu.br/handle/1044/1372. Acesso em: 16 fev. 2020.

ANJOS, Isa Regina Santos dos. Programa TEC NEP: avaliação de uma proposta de educação profissional inclusiva. 2006. Dissertação (Mestrado em Educação Especial) - Centro de Educação e Ciências Humanas, Universidade Federal de São Carlos, São Carlos, 2006. Disponível em: https://repositorio.ufscar.br/handle/ufscar/2949. Acesso em: 23 abr. 2020.

BASSO, Sabrina Pereira Soares; CAMPOS, Luciana Maria Lunardi. Licenciaturas em Ciências e Educação Inclusiva: a visão dos/as licenciandos/as. Revista Eletrônica de Educação, v. 13, n. 2, p. 554-571, 2019. Disponível em: http://www. reveduc.ufscar.br/index.php/reveduc/article/view/2522. Acesso em: 02 mar. 2020.

BELCHIOR, Luciney Florentina Gomes. Inclusão de estudantes com necessidades educacionais especiais nas instituições públicas de ensino médio no município de Ituiutaba. 2017. Dissertação (Mestrado em Estudos Profissionais Especializados em Educação) - Escola Superior de Educação, Instituto Politécnico do Porto. Porto, 2017. Disponível em: https:// recipp.ipp.pt/handle/10400.22/10473. Acesso em: 18 fev. 2020.

BORBA, Bruna Barros de. Os processos de aprendizagem e o Transtorno do Espectro do Autismo (TEA): do segundo ao terceiro ano do ensino fundamental. Cadernos do Aplicação, v. 33, n. 2, 2020. Disponível em: https://doi.org/10.22456/25954377.98853. Acesso em: 24 jan. 2021.

BRASIL. Política Nacional de educação especial na perspectiva da educação inclusiva. Brasília, DF: MEC, 2008. Disponível em: http://portal.mec.gov.br/arquivos/pdf/politicaeducespecial.pdf. Acesso em: 25 jan. 2021.

BRASIL. Conselho Nacional de Educação. Resolução CNE/CP no 1, de 18 de fevereiro de 2002. Institui Diretrizes Curriculares Nacionais para a Formação de Professores da Educação Básica, em nível superior, curso de licenciatura, de graduação plena. Brasília, DF, 2002a. Disponível em: http://portal.mec.gov.br/cne/arquivos/pdf/rcp01_02.pdf. Acesso em: 22 fev. 2020.

BRASIL. Conselho Nacional de Educação. Resolução CNE/CP nº 2, de $1^{\circ}$ de julho de 2015. Define as Diretrizes Curriculares Nacionais para a formação inicial em nível superior (cursos de licenciatura, cursos de formação pedagógica para graduados e cursos de segunda licenciatura) e para a formação continuada. Brasília, DF, 2015a. Disponível em: http://portal.mec.gov.br/docman/agosto-2017-pdf/70431-res-cne-cp-002-03072015-pdf/file. Acesso em: 23 abr. 2020.

BRASIL. Conselho Nacional de Educação. Resolução CNE/CP nº 2, de 20 de dezembro de 2019. Define as Diretrizes Curriculares Nacionais para a Formação Inicial de Professores para a Educação Básica e institui a Base Nacional Comum para a Formação Inicial de Professores da Educação Básica (BNC-Formação). Brasília, DF, 2020a. Disponível em: http://portal.mec.gov.br/docman/dezembro-2019-pdf/135951-rcp002-19/file. Acesso em: 23 abr. 2020.

BRASIL. Conselho Nacional de Educação. Parecer CNE/CP nº 5, de 28 de abril de 2020. Reorganização do Calendário Escolar e da possibilidade de cômputo de atividades não presenciais para fins de cumprimento da carga horária mínima anual, em razão da Pandemia da COVID-19. Brasília, DF, 2020b. Disponível em: http://portal.mec.gov.br/ index.php?option=com_docman\&view=download\&alias=14511-pcp005-20\&category_slud=marco-2020-pdf\&Itemid=30192. Acesso em: 31 out. 2020.

BRASIL. Decreto $n^{\circ}$ 10.502, de 30 de setembro de 2020. Institui a Política Nacional de Educação Especial: Equitativa, Inclusiva e com Aprendizado ao Longo da Vida. Brasília, DF, 2020c. Disponível em: http://www.planalto.gov.br/ ccivil_03/_ato2019-2022/2020/decreto/D10502.htm. Acesso em: 04 out. 2020.

BRASIL. Educação, Tecnologia e Profissionalização para alunos com Necessidades Educacionais Especiais. Documento Base Versão III. Brasília, DF, Secretaria de Educação Técnica e Profissionalizante, 2009.

BRASIL. Instituto Nacional de Estudos e Pesquisas Educacionais (Inep). Censo da Educação Básica: Resumo técnico, 2019. Brasília, DF, 2020d. Disponível em: https://download.inep.gov.br/publicacoes/institucionais/estatisticas_e_indicadores/resumo_tecnico_censo_da_educacao_basica_2019.pdf. Acesso em: 24 jan. 2021.

BRASIL. Instituto Nacional de Estudos e Pesquisas Educacionais (Inep). Sinopse Estatística da Educação Básica, 2019. Brasília, DF, 2020e. Disponível em: http://portal.inep.gov.br/web/guest/sinopses-estatisticas-da-educacao-basica. Acesso em: 22 fev. 2020.

BRASIL. Lei no 11.892, de 29 de dezembro de 2008. Institui a Rede Federal de Educação Profissional, Científica e Tecnológica, cria os Institutos Federais de Educação, Ciência e Tecnologia, e dá outras providências. Brasília, DF, $2008 \mathrm{a}$. Disponível em: http://www.planalto.gov.br/ccivil_03/_Ato2007-2010/2008/Lei/L11892.htm. Acesso em: 22 fev. 2020. 
BRASIL. Lei $n^{\circ}$ 12.772, de 28 de dezembro de 2012. Dispõe sobre a estruturação do Plano de Carreiras e Cargos de Magistério Federal; [...] e dá outras providências. Brasília, DF, 2012. Disponível em: http://www.planalto.gov.br/ ccivil_03/_Ato2011-2014/2012/Lei/L12772.htm. Acesso em: 12 jul. 2020.

BRASIL. Lei no 13.146, de 06 de julho de 2015. Institui a Lei Brasileira de Inclusão da Pessoa com Deficiência (Estatuto da Pessoa com Deficiência). Brasília, DF, 2015b. Disponível em: http://www.planalto.gov.br/ccivil_03/_ato2015-2018/2015/ lei/l13146.htm. Acesso em: 22 abr. 2020.

BRASIL. Lei $n^{\circ} 13.409$, de 28 de dezembro de 2016. Altera a Lei $n^{\circ} 12.711$, de 29 de agosto de 2012, para dispor sobre a reserva de vagas para pessoas com deficiência nos cursos técnico de nível médio e superior das instituições federais de ensino. Brasília, DF, 2016. Disponível em: http://www.planalto.gov.br/ccivil_03/_Ato2015-2018/2016/Lei/L13409. htm. Acesso em: 22 fev. 2020.

BRASIL. Supremo Tribunal Federal. Ação direta de inconstitucionalidade no 6590/DF. Relator: Ministro Dias Tóffoli. 2020f. Disponível em: <http://portal.stf.jus.br/processos/detalhe.asp?incidente=603650 >. Acesso em: 22 dez. 2020.

COSTA, Angelo Brandelli; ZOLTOWSKI, Ana Paula Couto. Como escrever um artigo de revisão sistemática. In: KOLLER, Sílvia Helena; COUTO, Maria Clara Pinheiro de Paula; HOHENDORFF, Jean Von (org.). Manual para produção científica. Porto Alegre: Penso, 2014. p. 55-70. [ISBN:978-85-65848-91-6].

COSTA, Luana Ugalde da. Desenvolvimento profissional de coordenadores do NAPNE do Instituto Federal do Acre. 2018. Dissertação (Mestrado Profissional em Ensino Tecnológico) - Instituto Federal de Educação, Ciência e Tecnologia do Amazonas, Manaus, 2018. Disponível em: http://repositorio.ifam.edu.br/jspui/handle/4321/357. Acesso em: 08 fev. 2020.

FERREIRA, Naidson Clayr Santos. Programa de formação em informática para professores no atendimento de alunos com deficiência visual. 2017. Tese (Doutorado em Educação Especial) - Centro de Educação e Ciências Humanas, Universidade Federal de São Carlos. São Carlos, 2017. Disponível em: https://repositorio.ufscar.br/handle/ufscar/9084. Acesso em: 19 fev. 2020.

FORTES, Vanessa Gosson Gadelha de Freitas. Formação continuada de professores do ensino médio integrado do Instituto Federal de Educação, Ciência e Tecnologia do Rio Grande do Norte (IFRN), na perspectiva da inclusão escolar de aluno com deficiência visual. 2017. Tese (Doutorado em Educação) - Centro de Educação, Universidade Federal do Rio Grande do Norte, Natal, 2017. Disponível em: https://repositorio.ufrn.br/jspui/handle/123456789/24143. Acesso em: 16 fev. 2020.

FREITAS, César Gomes de. Realidade e Perspectivas do Ensino Tecnológico para Pessoas com Deficiência na Amazônia Ocidental: o caso do Instituto Federal do Acre. 2017. Tese (Doutorado em Ensino em Biociências e Saúde) - Fundação Oswaldo Cruz, Instituto Oswaldo Cruz, Rio de Janeiro, 2017. Disponível em: https://bdtd.ibict.br/vufind/Record/ CRUZ_f1c72e17c0c9adf8695a9e44ff2cde50. Acesso em: 08 fev. 2020.

JANNUZZI, Gilberta de Martino. A educação do deficiente no Brasil: dos primórdios ao início do século XXI. Campinas: Autores Associados, 2012. [ISBN 85-7496-102-7].

JESUS, Denise Meyrelles de; EFFGEN, Adriana Pereira Siqueira. Formação docente e práticas pedagógicas: conexões, possibilidades e tensões. In: MIRANDA, Theresinha Guimarães; GALVÃO FILHO, Teófilo Alves (org.). O professor e a educação inclusiva: formação, práticas e lugares. Salvador, EDUFBA, 2012. [ISBN 978-85-232-1014-4]. Disponível em: https://repositorio.ufba.br/ri/handle/ri/12005. Acesso em: 25 abr. 2020.

KÖNIG, Franciele Rusch. Formação inicial e educação inclusiva: um olhar para cursos de licenciatura. 2019. Dissertação (Mestrado em Educação) - Centro de Educação, Universidade Federal de Santa Maria, Santa Maria, 2019. Disponível em: https://repositorio.ufsm.br/handle/1/18919. Acesso em: 16 mar. 2020.

LIMA, Cícero Batista dos Santos et al. Educação profissional e inclusão - ações do Napne e o currículo integrado para estudantes com necessidades específicas uma análise entre o real e o utópico. In: SILVA, Neidi Liziane Copetti da (org.). Relato dos professores sobre os desafios da atuação docente em diferentes contextos. Campo Grande: Editora Inovar, 2019. E-book. [ISBN 978-65-80476-14-5]. Disponível em: https://editorainovar.com.br/_files/200000172-5724c5724f/ Livro\%20-\%20RELATO\%20DOS\%20PROFESSORES\%20SOBRE\%20OS\%20DESAFIOS\%20DA\%20ATUA\%C3\%87\%C3\%83O\%20DOCENTE\%20EM\%20DIFERENTES\%20CONTEXTOS.pdf\#page=138. Acesso em: 17 fev. 2020.

LIRA, Jordana Tavares de. Avaliação de uma proposta de Educação Profissional Inclusiva: o olhar dos docentes do Campus Apodi do IFRN. 2018. Trabalho de Conclusão de Curso (Graduação) - Curso de Pedagogia, Centro de Educação, Universidade Federal do Rio Grande do Norte, Parnamirim/RN, 2018. Disponível em: https://monografias.ufrn. br/jspui/handle/123456789/7286. Acesso em: 17 fev. 2020.

MACEDO, Miriam; SILVA, Leila. Informação e sensibilização para a inclusão: ação do Napne na formação de professores. Ciclo Revista: Experiências em formação no IFGoiano, v. 02, n. 1, p. 29, 2017. Disponível em: https://ifgoiano. edu.br/periodicos/index.php/ciclo/article/viewFile/574/437. Acesso em: 17 fev. 2020. 
MAZZOTTA, Marcos José da Silveira. Educação especial no Brasil: história e políticas públicas. 6. ed. São Paulo: Cortez, 2011. [ISBN 978-85-249-1709-7].

MENEZES, André Luis et al. Percepções de professores da educação básica acerca do conceito de inclusão. Vidya, v. 36, n. 1, p. 1-13, 2016. DOI: 10.37781/vidya.v36i1.591.

MÔNICO, Patrícia Aparecida; MORGADO, Liz Amaral Saraiva; ORLANDO, Rosimeire Maria Formação inicial de professores na perspectiva inclusiva: levantamento de produções. Psicologia Escolar e Educacional. 2018, v. 22, n.spe, p. 41-48. Disponível em: http://www.scielo.br/pdf/pee/v22nspe/2175-3539-pee-22-spe-41.pdf. Acesso em: 10 mar. 2020.

MONTEIRO, Vívian de Faria Caixeta et al. Ciclo Revista: Experiências em Formação no IFGoiano, v. 2, n. 1, p. 7-8, 2017. Disponível em: https://ifgoiano.edu.br/periodicos/index.php/ciclo/article/viewFile/574/437. Acesso em: 29 mar. 2020.

MOURA, Katia Cristina Bezerra. A política de inclusão na educação profissional: o caso do Instituto Federal de Pernambuco/Campus Recife. 2013. Dissertação (Mestrado em Educação) - Universidade Federal da Paraíba, João Pessoa, 2013. Disponível em: https://repositorio.ufpb.br/jspui/handle/tede/4751. Acesso em: 25 jan. 2021.

NORONHA, Lílian Freire. Formação continuada de professores do ensino médio para a Educação Especial na perspectiva da educação inclusiva. 2017. Dissertação (Mestrado Profissional em Ensino Tecnológico) - Instituto Federal de Educação, Ciência e Tecnologia do Amazonas, Campus Manaus Centro, 2017. Disponível em: http://repositorio.ifam. edu.br/jspui/handle/4321/77. Acesso em: 08 fev. 2020.

OLIVEIRA, Rosilene Souza de. Ser professor na educação profissional e tecnologia: fazeres e saberes docentes do IF SERTÃO-PE. 2016. Dissertação (Mestrado em Educação e Diversidade) - Departamento de Ciências Humanas - Campus IV, Universidade do Estado da Bahia, Jacobina, 2016. Disponível em: http://www.saberaberto.uneb.br/ handle/20.500.11896/358. Acesso em: 24 jul. 2020.

ROSA, Milton; OLIVEIRA, Davidson Paulo Azevedo de; OREY, Daniel Clark. Delineando e conduzindo o método misto de pesquisa em investigações em educação matemática. Perspectivas da Educação Matemática, v. 8, número temático, p. 749-769, 2015.

SANTOS, Eliene Maria Sales. Formação continuada docente: a diversidade como princípio educativo no IFBA de Jacobina - Bahia. 2018. Dissertação (Mestrado Profissional em Educação e Diversidade) - Departamento de Ciências Humanas, Campus IV, Universidade do Estado da Bahia, Jacobina, 2018. Disponível em: https://portal.uneb.br/mped/ wp-content/uploads/sites/120/2018/12/TFCC-Eliene-2018.pdf. Acesso em: 19 fev. 2020.

SILVA, Rosilene Gonçalves. Desafios e possibilidades na inclusão de alunos com deficiência no PROEJA IFES campus Vitória. 2014. Dissertação (Mestrado em Educação) - Universidade Federal do Espírito Santo, Vitória, 2014. Disponível em: https://bdtd.ibict.br/vufind/Record/UFES_c705e03ac75865f05b7bea7d02d482a5. Acesso em: 08 fev. 2020.

SOUZA, Leigh Maria de; ALMEIDA, Gabriela Nogueira; XIMENES, Francimar Alves. Projeto de capacitação docente no IF Goiano: preparando professores para promover a inclusão de alunos com necessidades educacionais especiais. Ciclo Revista: Experiências em formação no IF Goiano, v. 02, n. 1, p. 42, 2017. Disponível em: https://ifgoiano.edu.br/ periodicos/index.php/ciclo/article/viewFile/574/437. Acesso em: 17 fev. 2020.

TASHAKKORI, Abbas; CRESWELL, John W. The new era of mixed methods. Journal of Mixed Methods Research, v. 1, n. 1, p. 3-7, jan. 2007. Disponível em: http://mmr.sagepub.com/content/1/1/3. Acesso em: 24 jul. 2020.

Data de submissão: 09/05/2021

Data de aceite: 03/07/2021 